\title{
Carboxylation and Decarboxylation of Aluminum Oxide Nanoparticles Using Bifunctional Carboxylic Acids and Octylamine
}

\author{
Shirin Alexander, ${ }^{1}$ Virginia Gomez, ${ }^{1}$ and Andrew R. Barron ${ }^{1,2,3}$ \\ ${ }^{1}$ Energy Safety Research Institute (ESRI), Swansea University Bay Campus, Fabian Way, Swansea SA1 8EN, UK \\ ${ }^{2}$ Department of Chemistry, Rice University, Houston, TX 77005, USA \\ ${ }^{3}$ Department of Materials Science and Nanoengineering, Rice University, Houston, TX 77005, USA \\ Correspondence should be addressed to Andrew R. Barron; arb@rice.edu
}

Received 4 December 2015; Accepted 27 January 2016

Academic Editor: Hua Zou

Copyright ( 2016 Shirin Alexander et al. This is an open access article distributed under the Creative Commons Attribution License, which permits unrestricted use, distribution, and reproduction in any medium, provided the original work is properly cited.

\begin{abstract}
The carboxylation of alumina nanoparticles (NPs), with bifunctional carboxylic acids, provides molecular anchors that are used for building more complexed structures via either physisorption or chemisorption. Colloidal suspensions of the NPs may be prepared by covalently bonding a series of carboxylic acids with secondary functional groups $\left(\mathrm{HO}_{2} \mathrm{C}-\mathrm{R}-\mathrm{X}\right)$ to the surface of the NPs: lysine $\left(\mathrm{X}=\mathrm{NH}_{2}\right)$, p-hydroxybenzoic acid $(\mathrm{X}=\mathrm{OH})$, fumaric acid $\left(\mathrm{X}=\mathrm{CO}_{2} \mathrm{H}\right)$, and 4-formylbenzoic acid $(\mathrm{X}=\mathrm{C}(\mathrm{O}) \mathrm{H})$. Subsequent reaction with octylamine at either $25^{\circ} \mathrm{C}$ or $70^{\circ} \mathrm{C}$ was investigated. Fourier transform IR-attenuated reflectance spectroscopy (FTIRATR), thermogravimetric analysis (TGA), and scanning electron microscopy (SEM) along with energy dispersive X-ray (EDX) analysis were used to characterize the bifunctionalized monolayers and/or multilayer corona surrounding the alumina NPs and investigate the reaction mechanism of octylamine with the functional groups (X) of the NPs. Except for the fumaric functionalized NPs, addition of octylamine to the functionalized NPs leads to removal of excess carboxylic acid corona from the surface via an amide formation. The extent of the multilayer is dependent on the strength of the acid $\cdots$ acid interaction.
\end{abstract}

\section{Introduction}

Metal oxide-based nanoparticles (NPs) are among the most commercially important nanoparticles with a wide range of applications, including fillers [1], preceramic materials allowing for controlled morphology and porosity [2,3], biological and biomedical applications [4-10], organic based electronic devices [11], coatings [12], water purification membranes [13$17]$, and enhanced oil recovery (EOR) $[18,19]$. To use oxide NPs in most of these applications, the particles need to be combined with organic moieties (resins, polymers, acids, etc.) in order to provide functionalized groups (molecular anchors) for further reactivity and miscibility with particular solvent systems for processing. In the case of aluminum oxide and iron oxide NPs, the most readily accessible and flexible organic functionality involves reaction of the surface with carboxylic acids $\left(\mathrm{HO}_{2} \mathrm{CR}\right)$. As such the carboxylate-oxide
NP interactions have been extensively studied with some even produced commercially [20-22]. The identity of the organic substituents (R) on the carboxylate group controls the physical properties of the functionalized NP. For example, simple aliphatic hydrocarbon and fluorocarbon chains $(\mathrm{R}=$ $\left.\mathrm{C}_{n} \mathrm{H}_{2 n+1} \mathrm{C}_{n} \mathrm{~F}_{2 n+1}\right)$ can be used for the creation of hydrophobic surfaces [20,23-25], while protic substituents (i.e., $\mathrm{OH}, \mathrm{NH}_{2}$, and $\mathrm{SO}_{3} \mathrm{H}$ ) can be used to create hydrophilic surfaces [13], enhance solubility [26], and facilitate further reactivity [27, 28].

We have shown that aluminum oxide wafers can be functionalized by different multifunctional acids [29], and self-assembled monolayer (SAM) or multilayers are formed depending on the type of acid used. It was also shown that octylamine coupling layers are created with the SAMs by either physisorption or chemisorption. Physisorption occurs via hydrogen bonding between the functional group of 
<smiles>NCCCCC(N)C(=O)O</smiles>

(a)

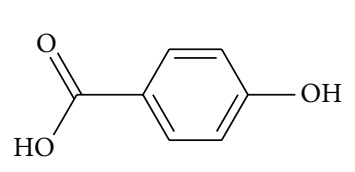

(b)<smiles>O=C(O)C=CC(=O)O</smiles>

(c)<smiles>O=Cc1ccc(C(=O)O)cc1</smiles>

(d)<smiles>CCCCCCCCN</smiles>

(e)

FIGURE 1: Carboxylic acids with various functional groups: (a) lysine $\left(\mathrm{pK}_{\mathrm{a}}: 2.18,8.95,10.53\right)$, (b) $p$-hydroxybenzoic acid (pK $\mathrm{p}_{\mathrm{a}}$ : 4.57, 9.46), (c) fumaric acid $\left(\mathrm{pK}_{\mathrm{a}}: 3.03,4.38\right)$, (d) 4-formylbenzoic acid $\left(\mathrm{pK}_{\mathrm{a}}: 3.84\right)$, and (e) octylamine $\left(\mathrm{pK}_{\mathrm{a}}: 10.65\right)$.

octylamine and the SAMs, thus leading to a $\mathrm{pH}$ dependency. In this work, however, we show the effect of octylamine on the carboxylic acid functionalized alumina NP as a decarboxylating agent rather than a coupling layer.

\section{Materials and Methods}

2.1. Materials. All the carboxylic acids and the amine shown in Figure 1 and the aluminum oxide nanoparticles (under the trade name of Aeroxide-Alu C) were obtained from Sigma Aldrich and were used as received. The unfunctionalized NPs are fluffy, white powders with specific surface area of $100 \pm$ $15 \mathrm{~m}^{2} \cdot \mathrm{g}^{-1}$ and average particle diameters of $12 \mathrm{~nm}$.

2.2. Characterization. Scanning electron microscopy (SEM) and associated energy dispersive X-ray (EDX) measurements were performed with a Hitachi Field Emission S-4800 scanning microscope. Samples were attached to a metal mount using carbon tape. Thermogravimetric/differential thermal analysis (TGA/DTA) experiments were conducted on a TA Instrument SDT Q600 using open alumina crucible under static airflow. The heating profile was equilibrated at $50^{\circ} \mathrm{C}$ and then ramped at $20^{\circ} \mathrm{C} \mathrm{min}^{-1}$. Fourier transform infrared (FTIR) measurements were carried out by Thermoscientific i510, recording spectra in the $400-4000 \mathrm{~cm}^{-1}$ region with 32 scans. Zeta potential measurements (triplicate) and dynamic light scattering (DLS) were carried out using a Malvern Zetasizer Nanoseries instrument at room temperature. Particles were dispersed using an ultrasonic bath before each measurement and acidity and basicity were adjusted using $0.1 \mathrm{M}$ of $\mathrm{HNO}_{3}$ and $\mathrm{KOH}$ as required. Nuclear magnetic resonance $\left({ }^{1} \mathrm{H}-\mathrm{NMR}\right)$ spectrum was recorded on a $500 \mathrm{MHz}$ Bruker machine at $25^{\circ} \mathrm{C}$ in deuterated methanol (MeOD).

2.3. Synthesis of Carboxylated Alumina Nanoparticles. In a modification of the literature procedures $[7,29]$, the aluminum oxide nanoparticles were refluxed overnight in aqueous solutions $(100 \mathrm{~mL})$ of the individual carboxylic acids (1:2 aluminum oxide to carboxylic acid mole equiv.). Lysine is readily soluble in water; however, in order to increase the solubility of the rest of the acids, the solution's $\mathrm{pH}$ was altered to above the $\mathrm{pK}_{\mathrm{a}}$ of each acid (see Figure 1) [30]. The functionalized particles were then washed with water, ethanol, and ether $(3 \times 10 \mathrm{~mL}$ each $)$ to remove unreacted carboxylic acids and oven dried at $80^{\circ} \mathrm{C}$ overnight.

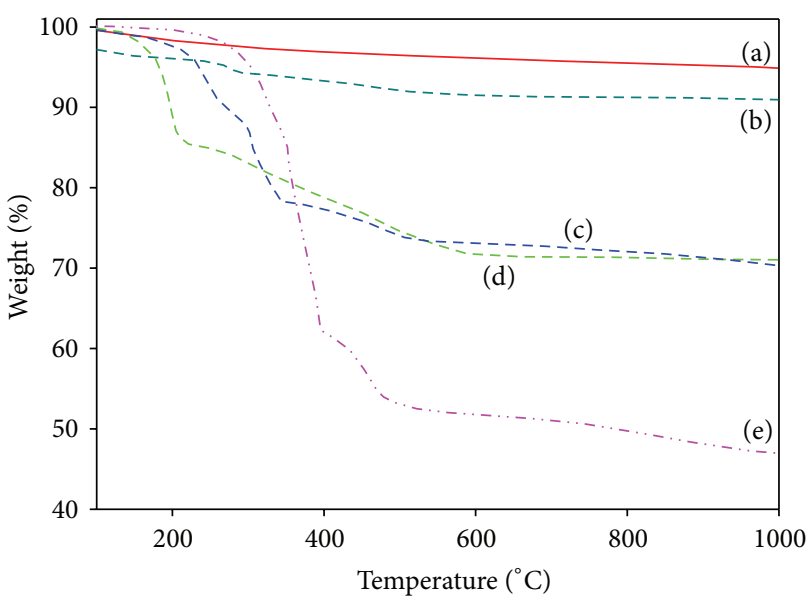

Figure 2: TGA of (a) unfunctionalized alumina NPs and alumina NPs functionalized with (b) 4-formylbenzoic acid, (c) $p$ hydroxybenzoic acid, (d) lysine, and (e) fumaric acid.

2.4. Reaction of Carboxylated Nanoparticles with Octylamine. The carboxylated aluminum NPs were stirred in solutions of octylamine (1:1.5 of acids on the surface, calculated using TGA data, to octylamine mole equiv.) in methanol (50 mL) and left stirring overnight either under refluxing conditions or at room temperature. The particles were then filtered out and were washed with $\mathrm{pH} 11$ aqueous solutions $(2 \times 10 \mathrm{~mL})$ and dried in air. Both products (prepared at room temperature or under refluxing conditions) were analyzed by TGA, IR, and EDX. In the case of the lysine functionalized NPs, the soluble side product was characterized by IR and ${ }^{1} \mathrm{H}-\mathrm{NMR}$ spectroscopy.

\section{Results and Discussion}

3.1. Carboxylation of Nanoparticles. The extent of functionalization of the as-prepared carboxylic acid functionalized alumina NPs was determined by TGA (Figure 2). The as-received alumina NPs show no significant mass loss $<800^{\circ} \mathrm{C}$ (Figure 2(a)); however, after functionalization with carboxylic acids, changes began at approximately $250^{\circ} \mathrm{C}$ with rapid weight loss occurring in the range $300-400^{\circ} \mathrm{C}$ (Figure 2(b-e)). The surface coverage (molecules per $\mathrm{nm}^{2}$ ) of 


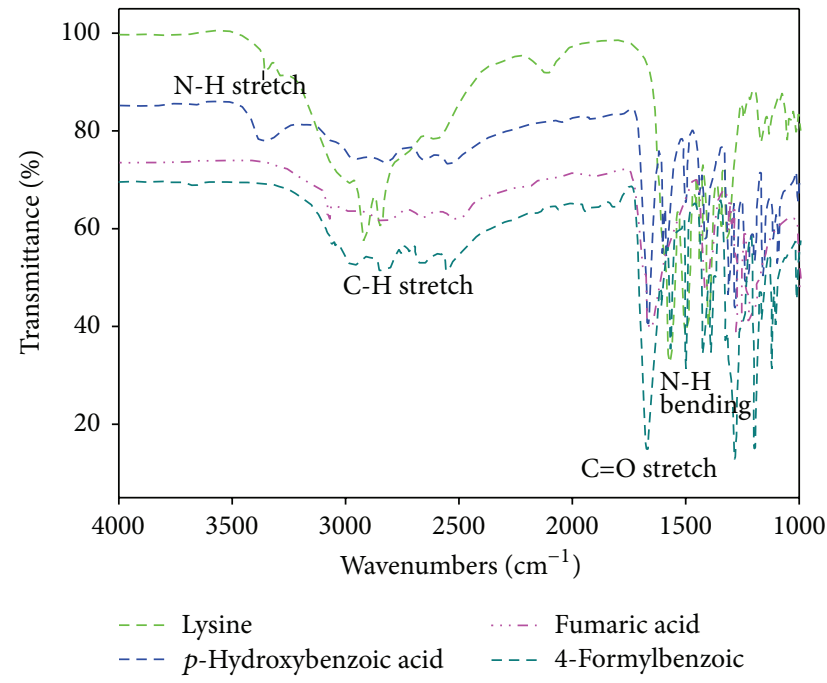

(a)

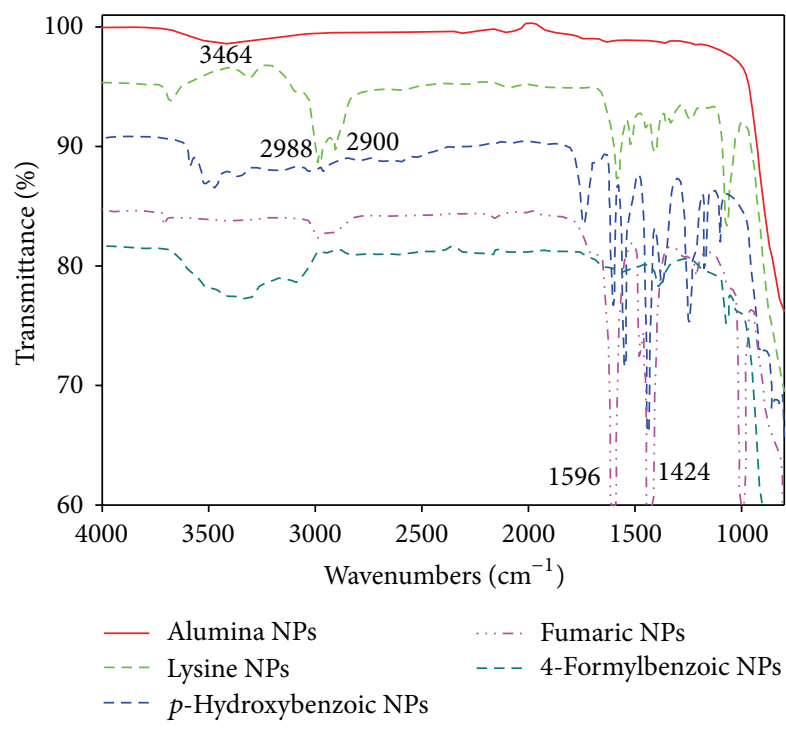

(b)

FIgURE 3: FTIR-ATR spectra of (a) neat carboxylic acids and (b) unfunctionalized alumina NPs, NPs functionalized with lysine, $p$ hydroxybenzoic acid, fumaric acid, and 4-formylbenzoic acid from top to bottom, respectively.

TABLE 1: Thermogravimetric analysis of the functionalized NPs.

\begin{tabular}{lccc}
\hline Sample & $\begin{array}{c}\text { Wt\% loss } \\
250-700^{\circ} \mathrm{C}\end{array}$ & $\begin{array}{c}\text { Residue } \\
@ 700^{\circ} \mathrm{C}\end{array}$ & $\begin{array}{c}\text { Grafting density } \\
\left(\mathrm{nm}^{-2}\right)\end{array}$ \\
\hline Lysine NPs & 28.0 & 72.0 & 16.0 \\
p-Hydroxybenzoic NPs & 26.5 & 73.5 & 15.7 \\
Fumaric NPs & 47.8 & 52.2 & 47.5 \\
4-Formylbenzoic NPs & 5.8 & 94.2 & 2.5 \\
\hline
\end{tabular}

the acids was calculated for the functionalized NPs (based on their weight loss) and is given in Table 1 .

As can be seen from the data in Table 1, the fumaric acid NPs showed a grafting density significantly higher than the other acids. Based upon a theoretical grafting density this result is consistent with the formation of self-assembled multilayers through the $-\mathrm{CO}_{2} \mathrm{H}$ functionality. Such a multilayer assembly was also observed on alumina wafers [29]. Derakhshan et al. also observed similar behavior on the interaction of fumaric acid and boehmite particles [22]. Fibrous structures of fumarate-boehmite got linked "in plane" to each other through their fumarate linkages and further multilayer structures led to the formation of cubic structures.

In order to confirm the covalent functionalization of the carboxylate moieties on the surface of the NPs, FTIRATR was performed and the data are shown in Figure 3. In all cases, after reaction of acids with the NP surface, the $\mathrm{C}=\mathrm{O}$ stretching band of the carboxylic acid (ca. $1700 \mathrm{~cm}^{-1}$ in Figure 3(a)) [22] is reduced and/or replaced by bands at $1425 \mathrm{~cm}^{-1}$ and $1590 \mathrm{~cm}^{-1}$ due to the symmetric and asymmetric stretches of carbonyls in bidentate bridging mode (Figure 3(b)) [22, 31]. The broad band at $3464 \mathrm{~cm}^{-1}$ of the unfunctionalized alumina NPs (Figure 3(b)) is due to the presence of hydrogen bonded $\mathrm{OH}$ groups on the nanoparticle
TABLE 2: Energy dispersive X-ray (EDX) analysis (atom $\% \pm 1.5)$ of native and carboxylic acid functionalized NPs.

\begin{tabular}{lccccc}
\hline Surface & $\mathrm{C}$ & $\mathrm{Al}$ & $\mathrm{O}$ & $\mathrm{N}$ & $\mathrm{C}: \mathrm{Al}$ \\
\hline Alumina NP & 2.9 & 30.9 & 66.1 & - & 0.09 \\
Lysine NPs & 16.2 & 24.6 & 56.2 & 3.0 & 0.65 \\
p-Hydroxybenzoic acid NPs & 31.7 & 20.5 & 47.8 & - & 1.54 \\
Fumaric acid NPs & 31.0 & 20.6 & 47.9 & - & 1.50 \\
4-Formylbenzoic acid NPs & 4.2 & 30.1 & 65.7 & - & 0.14 \\
\hline
\end{tabular}

surfaces [22], which is decreased upon reaction with the carboxylic acid and replaced by concomitant increase in the aliphatic/aromatic C-H stretches at around $2800 \mathrm{~cm}^{-1}$ to $3200 \mathrm{~cm}^{-1}$ as is shown in Figure 3(b).

Additional characterization of functionalized particles with carboxylic acids was undertaken by EDX analysis. The EDX analysis, shown in Table 2, indicates that the surface of the unfunctionalized particles on average is composed of aluminum (30.9\%) and oxygen (66.1\%) and small percentage of adventitious carbon (2.9\%). The $\mathrm{Al}: \mathrm{O}$ ratio $(0.47)$ is consistent with the hydrated nature of the NPs observed in the IR spectrum (Figure 3(b)). As would be expected, functionalization of the NPs with the acids increases the carbon composition with a decrease in the aluminum content (Table 2). The smallest increase in carbon \% is obtained for 4-formylbenzoic NPs with only $1.3 \mathrm{C} \%$ increase, which correlates with the TGA data that showed the smallest grafting density for these NPs. There is also a small increase in the $\mathrm{C}: \mathrm{Al}$ ratio (0.14) as compared to the unfunctionalized NPs (0.09).

The surface charge of the nanoparticles and their calculated isoelectric points (IEP) were achieved using zeta potential measurements. Figure 4 shows a plot of zeta potential 


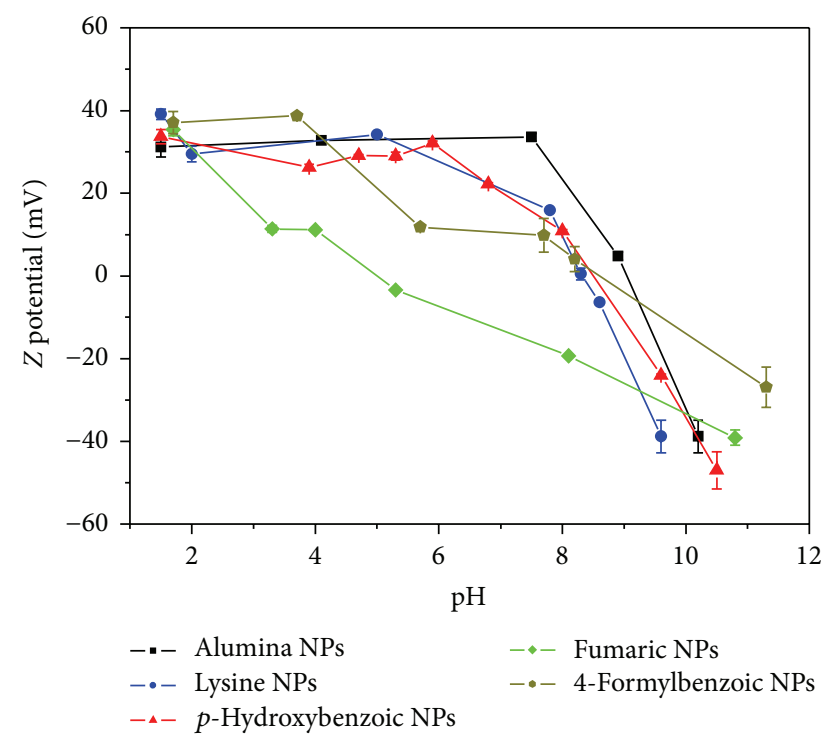

FIGURE 4: Zeta potential values of the different NPs versus $\mathrm{pH}$ in aqueous suspensions.

versus $\mathrm{pH}$ for the four functionalized alumina NPs and the native alumina NPs. The data can be used to determine the approximated isoelectric point (IEP) of the particles. Generally, if the IEP is $<7$ the surface is considered acidic and over $\mathrm{pH} 7$ the surface is basic [32]. As expected, the reference alumina NPs show an IEP value of $\mathrm{pH} 9.0$ close to the values obtained for pseudoboehmite [33]. Figure 4 shows that lysine NPs, $p$-hydroxybenzoic acid NPs, and 4-formylbenzoic acid NPs have isoelectric points between $\mathrm{pH} 8$ and 10. On the other hand, the fumaric acid functionalized surfaces show a significant change in their surface behavior being more acidic than alumina NPs. These particles have an isoelectric point close to $\mathrm{pH} 5$ due to the presence of an additional negatively charged carboxylic group on their surfaces. A similar effect in the IEP behavior has been observed by Meder et al. when functionalizing alumina NPs with carboxylic acids [5].

As $\mathrm{pH}$ increases, the particle size for carboxylated particles increases. This is due to the agglomeration and seeded particle growth [34]. The dissolution of aluminium oxides is at its minimum in the neutral $\mathrm{pH}$ range [32]; thus the hydrodynamic diameter of the functionalized nanoparticles was measured at $\mathrm{pH}$ range 4-5 to avoid dissolution processes. Figure 5 shows differences in the agglomeration state of the samples due to their differences in particle surface behavior. All the nanoparticles showed hydrodynamic diameter distributions around $100 \mathrm{~nm}$ at $\mathrm{pH}$ values between 4 and 5. The fumaric acid functionalized NPs show agglomeration in this $\mathrm{pH}$ range and this is because this $\mathrm{pH}$ is close to the isoelectric point as defined by the zeta potential results (Figure 4).

3.2. Addition of the Octylamine to the Functionalized Nanoparticles. In our recent work we showed that the carboxylated surfaces could undergo further reactivity via their surface functional groups [29]. Two methods (immersing and refluxing) were used for further coating of the aluminum surfaces and the analysis results confirmed that the coupling
TABLE 3: Thermogravimetric analysis of the functionalized NPs reacted with octylamine at $25^{\circ} \mathrm{C}$ and $70^{\circ} \mathrm{C}$.

\begin{tabular}{lccc}
\hline Sample & $\begin{array}{c}\text { Reaction temp. } \\
\left({ }^{\circ} \mathrm{C}\right)\end{array}$ & $\begin{array}{c}\text { Wt\% loss } \\
250-700^{\circ} \mathrm{C}^{\mathrm{a}}\end{array}$ & $\begin{array}{c}\text { Residue } \\
@ 700^{\circ} \mathrm{C}^{\mathrm{a}}\end{array}$ \\
\hline \multirow{2}{*}{ Lysine NPs } & 25 & 17.4 & 82.6 \\
& 70 & 9.9 & 90.1 \\
p-Hydroxybenzoic NPs & 25 & 18.1 & 81.9 \\
& 70 & 18.1 & 81.9 \\
Fumaric NPs & 25 & 48.0 & 52.0 \\
& 70 & 48.5 & 51.5 \\
4-Formylbenzoic NPs & 25 & 6.6 & 93.4 \\
& 70 & 6.8 & 93.2 \\
\hline
\end{tabular}

${ }^{\mathrm{a}}$ Compare to values for carboxylate NPs given in Table 1.

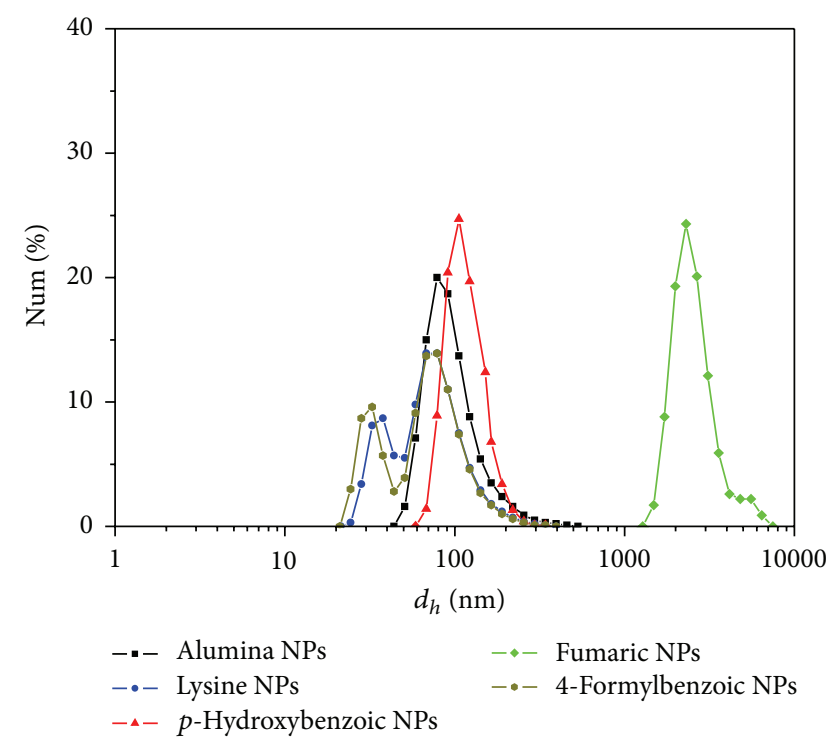

FIGURE 5: Hydrodynamic diameter distributions of the different NPs in aqueous suspensions at $\mathrm{pH}$ range 4-5.

self-assembled layer is $\mathrm{pH}$ responsive and reversible at lower $\mathrm{pH}$ under the first method and mainly irreversible under the second method based on the outer functional group of the self-assembled layers. The same experiments were carried out on the carboxylic acid functionalized alumina NPs; however, the results were unexpected. The TGA data, shown in Table 3, revealed that upon reaction of the NPs with octylamine (Figure 1(e)) the weight loss is smaller in all cases apart from fumaric acid NPs, whose weight loss is larger. The EDX analysis of the NPs after reaction with octylamine is consistent with the appropriate TGA data. Apart from the fumaric acid NPs, the carbon content decreases, regardless of the reaction temperature; see Table 4; however, the decrease in $\mathrm{C} \%$ is higher for the products of the reaction at $70^{\circ} \mathrm{C}$ as compared to those reacted at $25^{\circ} \mathrm{C}$. Clearly, the NPs are not reacting in an analogous manner to that observed for alumina surfaces [29].

To have a better understanding of the NPs functionalization (or defunctionalization) after the addition of octylamine 
TABLE 4: Energy dispersive X-ray (EDX) analysis $($ atom\% \pm 1.5$)$ of the various carboxylic acid functionalized NPs after reaction with octylamine.

\begin{tabular}{|c|c|c|c|c|c|c|}
\hline Reaction & Temp. $\left({ }^{\circ} \mathrm{C}\right)$ & $\mathrm{C}$ & $\mathrm{Al}$ & $\mathrm{O}$ & $\mathrm{N}$ & $\mathrm{C}: \mathrm{Al}$ \\
\hline \multirow{2}{*}{ Lysine NPs + octylamine } & 25 & 28.8 & 26.1 & 44.5 & 0.5 & 1.1 \\
\hline & 70 & 4.9 & 31.9 & 60.9 & 0.5 & 0.15 \\
\hline \multirow{2}{*}{ p-Hydroxybenzoic acid NPs + octylamine } & 25 & 10.4 & 28.7 & 60.7 & 0.1 & 0.36 \\
\hline & 70 & 7.7 & 30.8 & 60.7 & 0.6 & 0.25 \\
\hline \multirow{2}{*}{ Fumaric acid NPs + octylamine } & 25 & 32.0 & 20.4 & 47.1 & 0.5 & 1.56 \\
\hline & 70 & 31.8 & 19.0 & 48.9 & 0.6 & 1.67 \\
\hline \multirow{2}{*}{ 4-Formylbenzoic acid NPs + octylamine } & 25 & 2.9 & 41.12 & 55.9 & - & 0.07 \\
\hline & 70 & 2.8 & 31.1 & 66.3 & 0.4 & 0.09 \\
\hline
\end{tabular}

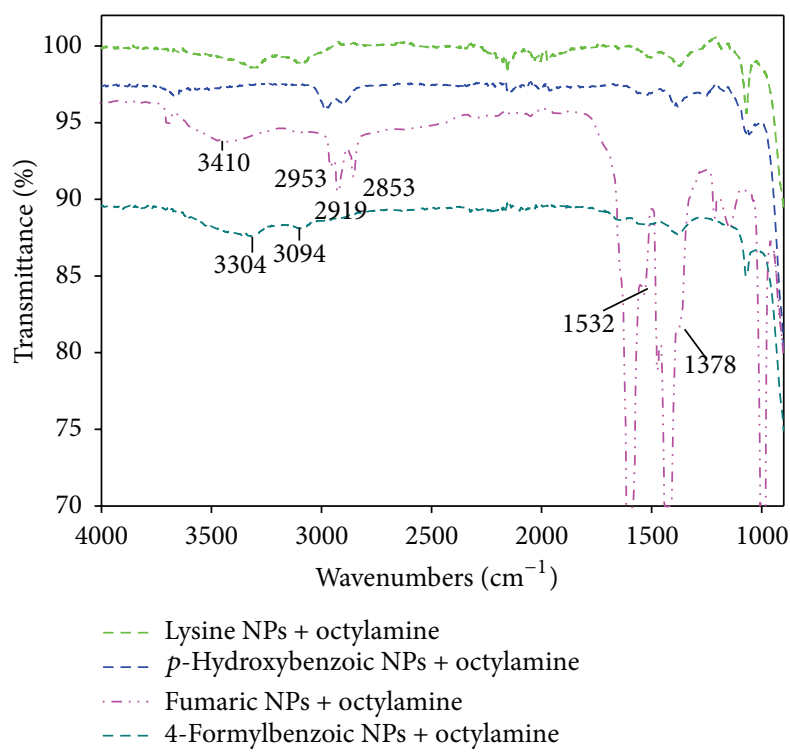

FIGURE 6: FTIR-ATR spectra of all the functionalized NPs, reacted with octylamine (refluxed).

the particles were studied by FTIR. Figure 6 shows the IR spectra of all the functionalized NPs after addition of octylamine. Based on the TGA and EDX results, fumaric acid NPs are the only particles that did not lose their functional groups upon addition of octylamine and this was confirmed by FTIR. Comparing Figure 6 with Figure 3(b) shows that two characteristic peaks of carboxylic acids bidentate modes at $1425 \mathrm{~cm}^{-1}$ and $1590 \mathrm{~cm}^{-1}$ reduced significantly upon reaction with octylamine for all the samples, except for fumaric acid NPs. There are peaks in all cases that feature octylamine, for example, three defined peaks at 2853, 2919, and $2953 \mathrm{~cm}^{-1}$ characteristic of symmetric and asymmetric $-\mathrm{CH}_{2}$ and asymmetric $-\mathrm{CH}_{3}$ stretches and the broad peaks at 3094$3410 \mathrm{~cm}^{-1}$ due to the presence of the secondary amide/N$\mathrm{H}$ stretches $[7,11,35]$. This indicates that primary role of the octylamine is to remove the majority of the carboxylic acid groups adsorbed on the surface but it secondarily reacts with the surface functional groups of the carboxylic acids via chemical reaction and/or hydrogen bonding as was seen for the alumina wafers [29].

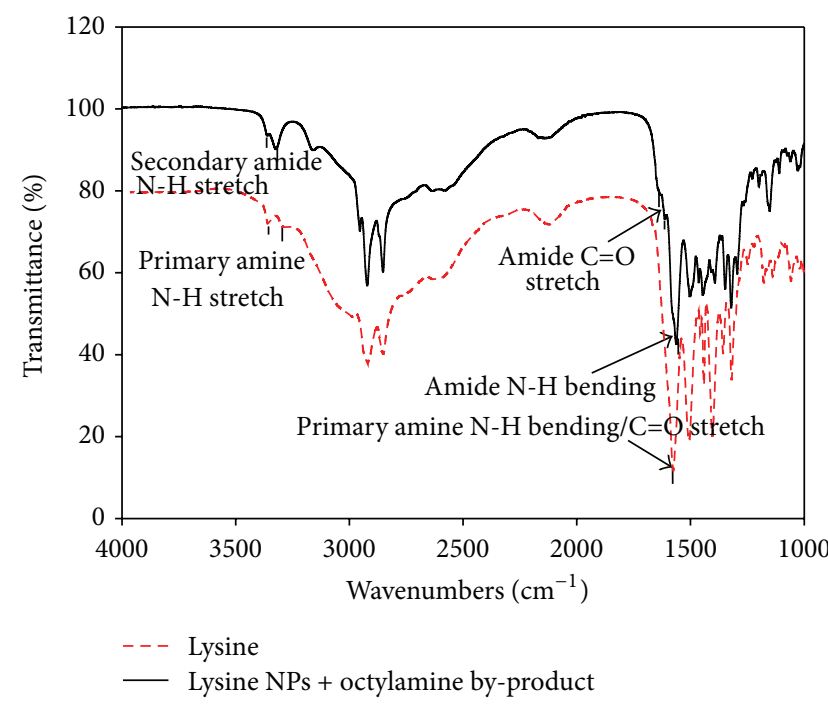

FIGURE 7: The FTIR spectra of the pure lysine and the filtrate solutions of the lysine NPs reacted with octylamine.

Carboxylic acids and amines react together to form salts, and strong heating (to remove water) of these salts leads to amide formation $[36,37]$. There are various factors influencing the yield of the reaction, including stirring conditions, temperature, solvent, and reagent's concentration [38]. The removal of the carboxylate from the surface of the NPs suggests that the reaction with excess of octylamine may lead to formation of an amide. To confirm this proposal the filtrate solutions of the lysine NPs reacted with octylamine were analyzed by FTIR and NMR and are shown in Figures 7 and 8 , respectively.

The lysine IR spectrum is compared with the reaction byproduct in Figure 7. As can be seen, there is evidence of both lysine and amide in the solutions (rather than just unreacted octylamine). Peaks at 3169,3320 , and $3360 \mathrm{~cm}^{-1}$ are due to secondary amide $\mathrm{N}-\mathrm{H}$ stretches as well as primary amine N$\mathrm{H}$ stretches, and the strong peak at $1568 \mathrm{~cm}^{-1}$ is characteristic of amide $\mathrm{N}-\mathrm{H}$ bending. It should be noted that the small peak is at $1620 \mathrm{~cm}^{-1}$; this peak is due to amide $\mathrm{C}=\mathrm{O}$ stretches that partially overlap the N-H bending mode. The NMR spectrum from the filtrate (Figure 8) shows the presence of the amide $\mathrm{N}-\underline{\mathrm{H}}$ at $3.28 \mathrm{ppm}$. If there was only amide present in the 


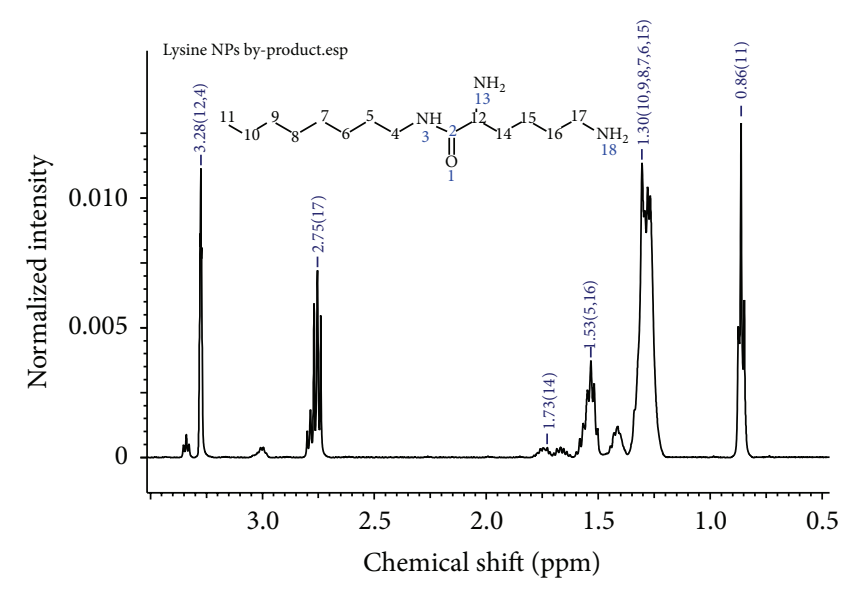

Figure $8:{ }^{1} \mathrm{H}-\mathrm{NMR}$ profile for byproduct of the lysine NPs reacted with octylamine. Peak assignment is as follows: $\delta$ (ppm) $0.86\left[3 \mathrm{H}, \mathrm{t},-\mathrm{CH}{ }_{3}\right]$, 1.3-1.7 (18H, m, aliphatic C- $\mathrm{H}), 2.75\left(2 \mathrm{H}, \mathrm{m},-\mathrm{CH}_{2}-\mathrm{NH}_{2}-\right)$, and $3.28\left(2 \mathrm{H}, \mathrm{m},-\mathrm{CH}_{2}-\mathrm{NH}-\right)$. The numbers on top of each peak represent the atom on the shown structure.

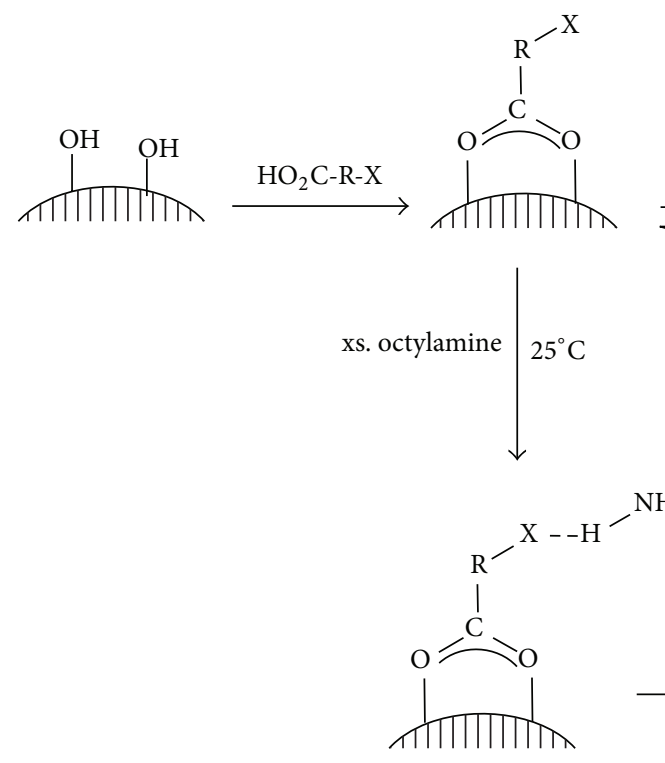

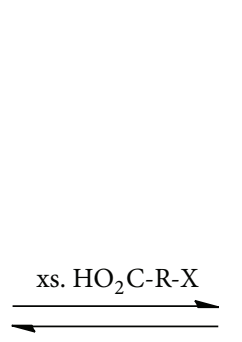

Octylamine

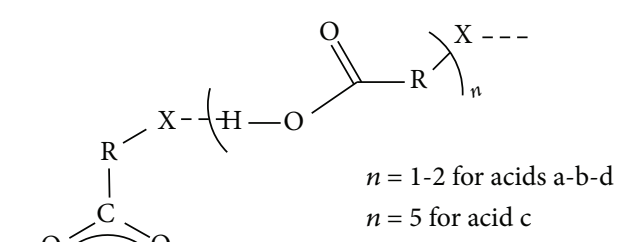

$n=5$ for acid c<smiles>C#CC1COC=COC(C)C1</smiles>

(2)

.

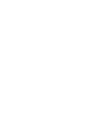


amine... carboxylic acid or phenol... carboxylic acid interactions [40, 41]. The greater strength of the carboxylic acid dimer involving cyclic dimers with two strong $\mathrm{C}=\mathrm{O} \cdots \mathrm{H}-\mathrm{O}$ hydrogen bonds $[42,43]$ results in an extensive multilayer structure for the fumaric acid derivative.

Upon addition of octylamine to the 4-formylbenzoic, lysine, and $p$-hydroxybenzoic derivatives the excess acid is removed by the formation of soluble ammonium carboxylic acid salts or amides. What remain are the covalently bound carboxylate moieties, to which excess octylamine reacts through either hydrogen bonding. In the case of the 4formylbenzoic derivative heating the reaction mixture results in hydration and the formation of the appropriate amide. A schematic representation of this process is shown in Figure 9. We note that carboxylic acids have been shown to react with amine terminated functionalized metal oxide NPs [44], and the coupling represented herein signifies the observed reaction.

\section{Conclusions}

Functionalization of alumina NPs with various bifunctional carboxylic acids results in chemically bonded multilayers whose extent depends on the surface functional groups. For example, fumaric acid functionalized NPs undergo reaction with at least a 4 -fold excess of fumaric acid to create a stable corona. There have previously been reports of the significance of protein corona about NPs [45, 46]; however, little has been investigated for simpler functionality. We have shown that the carboxylic acid corona can be partially or fully removed by using an amine (octylamine) as a reagent wash, under certain temperature, stirring condition, and concentration. This is in contrast to the results obtained for thin films, where a simple $\mathrm{pH}$ responsive coupling layer was formed via a hydrogen bonding between the amine and the outer layer of the functionalized wafers [29]. The only functionalized NPs unaffected were fumaric acid NPs, which retained their functionality as well as gaining some interaction with octylamine. As such the treatment of bifunctional carboxylic acid $\left(\mathrm{HO}_{2} \mathrm{C}-\mathrm{R}-\mathrm{X}\right)$ functionalized alumina NPs with an amine, such as octylamine, should be a routine process for the purification of the functionalized NPs to ensure the removal of excess carboxylic acid. We note, however, that this appears to be limited by the acid... acid interaction, since, as in the case of fumaric acid, removal of the functional groups does not happen and/or hardly happens.

\section{Conflict of Interests}

The authors declare that there is no conflict of interests regarding the publication of this paper.

\section{Acknowledgments}

Financial support was provided by the Sêr Cymru National Research Network in Advanced Engineering and Materials and the Robert A. Welch Foundation (C-0002). One of the authors (Andrew R. Barron) acknowledges the financial support provided by the Welsh Government Sêr Cymru Chair Programme.

\section{References}

[1] P. Colombo, E. Bernardo, and G. Parcianello, "Multifunctional advanced ceramics from preceramic polymers and nano-sized active fillers," Journal of the European Ceramic Society, vol. 33, no. 3, pp. 453-469, 2013.

[2] C. D. Jones, M. Fidalgo, M. R. Wiesner, and A. R. Barron, "Alumina ultrafiltration membranes derived from carboxylatealumoxane nanoparticles," Journal of Membrane Science, vol. 193, no. 2, pp. 175-184, 2001.

[3] M. M. Cortalezzi, J. Rose, G. F. Wells, J.-Y. Bottero, A. R. Barron, and M. R. Wiesner, "Ceramic membranes derived from ferroxane nanoparticles: a new route for the fabrication of iron oxide ultrafiltration membranes," Journal of Membrane Science, vol. 227, no. 1-2, pp. 207-217, 2003.

[4] F. Meder, C. Brandes, L. Treccani, and K. Rezwan, "Controlling protein-particle adsorption by surface tailoring colloidal alumina particles with sulfonate groups," Acta Biomaterialia, vol. 9, no. 3, pp. 5780-5787, 2013.

[5] F. Meder, T. Daberkow, L. Treccani et al., "Protein adsorption on colloidal alumina particles functionalized with amino, carboxyl, sulfonate and phosphate groups," Acta Biomaterialia, vol. 8, no. 3, pp. 1221-1229, 2012.

[6] I. M. Sadiq, B. Chowdhury, N. Chandrasekaran, and A. Mukherjee, "Antimicrobial sensitivity of Escherichia coli to alumina nanoparticles," Nanomedicine: Nanotechnology, Biology, and Medicine, vol. 5, no. 3, pp. 282-286, 2009.

[7] R. A. Horch, N. Shahid, A. S. Mistry, M. D. Timmer, A. G. Mikos, and A. R. Barron, "Nanoreinforcement of poly(propylene fumarate)-based networks with surface modified alumoxane nanoparticles for bone tissue engineering," Biomacromolecules, vol. 5, no. 5, pp. 1990-1998, 2004.

[8] C. Walkey, S. Das, S. Seal et al., "Catalytic properties and biomedical applications of cerium oxide nanoparticles," Environmental Science: Nano, vol. 2, no. 1, pp. 33-53, 2015.

[9] M. Iv, N. Telischak, D. Feng, S. J. Holdsworth, K. W. Yeom, and H. E. Daldrup-Link, "Clinical applications of iron oxide nanoparticles for magnetic resonance imaging of brain tumors," Nanomedicine, vol. 10, no. 6, pp. 993-1018, 2015.

[10] Y. C. Rajan, B. S. Inbaraj, and B. H. Chen, "Synthesis and characterization of $\operatorname{poly}(\gamma$-glutamic acid)-based alumina nanoparticles with their protein adsorption efficiency and cytotoxicity towards human prostate cancer cells," RSC Advances, vol. 5, no. 20, pp. 15126-15139, 2015.

[11] S. Gupta, P. C. Ramamurthy, and G. Madras, "Synthesis and characterization of flexible epoxy nanocomposites reinforced with amine functionalized alumina nanoparticles: a potential encapsulant for organic devices," Polymer Chemistry, vol. 2, no. 1, pp. 221-228, 2011.

[12] U. Palanchoke, H. Kurz, R. Noriega et al., "Tuning the plasmonic absorption of metal reflectors by zinc oxide nano particles: application in thin film solar cells," Nano Energy, vol. 6, pp. 167172, 2014.

[13] S. J. Maguire-Boyle and A. R. Barron, "A new functionalization strategy for oil/water separation membranes," Journal of Membrane Science, vol. 382, no. 1-2, pp. 107-115, 2011.

[14] S. J. Maguire-Boyle, M. V. Liga, Q. Li, and A. R. Barron, "Alumoxane/ferroxane nanoparticles for the removal of viral 
pathogens: the importance of surface functionality to nanoparticle activity," Nanoscale, vol. 4, no. 18, pp. 5627-5632, 2012.

[15] M. Hua, S. Zhang, B. Pan, W. Zhang, L. Lv, and Q. Zhang, "Heavy metal removal from water/wastewater by nanosized metal oxides: a review," Journal of Hazardous Materials, vol. 211212, pp. 317-331, 2012.

[16] S. K. Brar, M. Verma, R. D. Tyagi, and R. Y. Surampalli, "Engineered nanoparticles in wastewater and wastewater sludgeevidence and impacts," Waste Management, vol. 30, no. 3, pp. 504-520, 2010.

[17] A. Gholami, A. R. Moghadassi, S. M. Hosseini, S. Shabani, and F. Gholami, "Preparation and characterization of polyvinyl chloride based nanocomposite nanofiltration-membrane modified by iron oxide nanoparticles for lead removal from water," Journal of Industrial and Engineering Chemistry, vol. 20, no. 4, pp. 1517-1522, 2014.

[18] L. Hendraningrat and O. Torsæter, "Metal oxide-based nanoparticles: revealing their potential to enhance oil recovery in different wettability systems," Applied Nanoscience, vol. 5, no. 2, pp. 181-199, 2014.

[19] H. Son, H. Kim, G. Lee, J. Kim, and W. Sung, "Enhanced oil recovery using nanoparticle-stabilized oil/water emulsions," Korean Journal of Chemical Engineering, vol. 31, no. 2, pp. 338342, 2014.

[20] A. R. Barron, "The interaction of carboxylic acids with aluminium oxides: Journeying from a basic understanding of alumina nanoparticles to water treatment for industrial and humanitarian applications," Dalton Transactions, vol. 43, no. 22, pp. 8127-8143, 2014.

[21] A. A. Derakhshan and L. Rajabi, "Review on applications of carboxylate-alumoxane nanostructures," Powder Technology, vol. 226, pp. 117-129, 2012.

[22] A. A. Derakhshan, L. Rajabi, and H. Karimnezhad, "Morphology and production mechanism of the functionalized carboxylate alumoxane micro and nanostructures," Powder Technology, vol. 225, pp. 156-166, 2012.

[23] J.-C. Liu, J.-H. Jean, and C. C. Li, "Dispersion of nano-sized ? $\gamma$ alumina powder in non-polar solvents," Journal of the American Ceramic Society, vol. 89, no. 3, pp. 882-887, 2006.

[24] R. J. Jouet, A. D. Warren, D. M. Rosenberg, V. J. Bellitto, K. Park, and M. R. Zachariah, "Surface passivation of bare aluminum nanoparticles using perfluoroalkyl carboxylic acids," Chemistry of Materials, vol. 17, no. 11, pp. 2987-2996, 2005.

[25] S. Alexander, J. Eastoe, A. M. Lord, F. Guittard, and A. R. Barron, "Branched hydrocarbon low surface energy materials for superhydrophobic nanoparticle derived surfaces," ACS Applied Materials \& Interfaces, vol. 8, no. 1, pp. 660-666, 2016.

[26] S. Çinar and M. Akinc, "Ascorbic acid as a dispersant for concentrated alumina nanopowder suspensions," Journal of the European Ceramic Society, vol. 34, no. 8, pp. 1997-2004, 2014.

[27] C. T. Vogelson, A. Keys, C. L. Edwards, and A. R. Barron, "Molecular coupling layers formed by reactions of epoxy resins with self-assembled carboxylate monolayers grown on the native oxide of aluminium," Journal of Materials Chemistry, vol. 13, no. 2, pp. 291-296, 2003.

[28] S. Alexander, C. W. Dunnill, and A. R. Barron, "Assembly of porous hierarchical copolymers/resin proppants: new approaches to smart proppant immobilization via molecular anchors," Journal of Colloid and Interface Science, vol. 466, pp. 275-283, 2016.

[29] S. Alexander, L. Morrow, A. M. Lord, C. W. Dunnill, and A. R. Barron, "pH-responsive octylamine coupling modification of carboxylated aluminium oxide surfaces," Journal of Materials Chemistry A, vol. 3, no. 18, pp. 10052-10059, 2015.

[30] W. M. Haynes, CRC Handbook of Chemistry and Physics, Taylor \& Francis, London, UK, 93rd edition, 2014.

[31] J. van den Brand, O. Blajiev, P. C. J. Beentjes, H. Terryn, and J. H. W. de Wit, "Interaction of anhydride and carboxylic acid compounds with aluminum oxide surfaces studied using infrared reflection absorption spectroscopy," Langmuir, vol. 20, no. 15, pp. 6308-6317, 2004.

[32] A. W. Adamson and A. P. Gast, Physical Chemistry of Surfaces, John Wiley \& Sons, 6th edition, 1997.

[33] A. R. Auxilio, P. C. Andrews, P. C. Junk et al., "Functionalised pseudo-boehmite nanoparticles as an excellent adsorbent material for anionic dyes," Journal of Materials Chemistry, vol. 18, no. 21, pp. 2466-2474, 2008.

[34] C. T. Vogelson and A. R. Barron, "Particle size control and dependence on solution $\mathrm{pH}$ of carboxylate-alumoxane nanoparticles," Journal of Non-Crystalline Solids, vol. 290, no. 2-3, pp. 216-223, 2001.

[35] D. Williams, I. Fleming, and E. Pretsch, Spectroscopic Methods in Organic Chemistry, McGraw-Hill, New York, NY, USA, 4th edition, 1989.

[36] H. Charville, Direct amide formation between carboxylic acids and amines: mechanism and development of novel catalytic solutions [Ph.D. thesis], Durham University, Durham, UK, 2012.

[37] J. A. Mitchell and E. E. Reid, "The preparation of aliphatic amides," Journal of the American Chemical Society, vol. 53, no. 5, pp. 1879-1883, 1931.

[38] L. Perreux, A. Loupy, and F. Volatron, "Solvent-free preparation of amides from acids and primary amines under microwave irradiation," Tetrahedron, vol. 58, no. 11, pp. 2155-2162, 2002.

[39] Y. Koide and A. R. Barron, " $\left[\mathrm{Al}_{5}\left({ }^{t} \mathrm{Bu}\right)_{5}\left(\mu_{3}-\mathrm{O}\right)_{2}\left(\mu_{3}-\mathrm{OH}\right)_{2}(\mu-\right.$ $\left.\mathrm{OH})_{2}\left(\mu-\mathrm{O}_{2} \mathrm{CPh}\right)_{2}\right]$ : a model for the interaction of carboxylic acids with boehmite," Organometallics, vol. 14, no. 8, pp. 40264029, 1995.

[40] R. Taylor and O. Kennard, "Hydrogen-bond geometry in organic crystals," Accounts of Chemical Research, vol. 17, no. 9, pp. 320-326, 1984.

[41] G. C. Pimentel and A. L. McClellan, The Hydrogen Bond, Freeman, San Francisco, Calif, USA, 1960.

[42] J. Chen, C. L. Brooks III, and H. A. Scheraga, "Revisiting the carboxylic acid dimers in aqueous solution: interplay of hydrogen bonding, hydrophobic interactions, and entropy," The Journal of Physical Chemistry B, vol. 112, no. 2, pp. 242-249, 2008.

[43] D. A. Wierda, T. Feng, and A. R. Barron, "Molecular structure of $\alpha$-trans-cinnamic acid," Acta Crystallographica Section C, vol. 45, no. 2, pp. 338-339, 1989.

[44] A. Kockmann, J. Hesselbach, S. Zellmer, A. Kwade, and G. Garnweitner, "Facile surface tailoring of metal oxide nanoparticles via a two-step modification approach," RSC Advances, vol. 5, no. 75, pp. 60993-60999, 2015.

[45] S. Ritz, S. Schöttler, N. Kotman et al., "Protein corona of nanoparticles: distinct proteins regulate the cellular uptake," Biomacromolecules, vol. 16, no. 4, pp. 1311-1321, 2015.

[46] E. Casals, T. Pfaller, A. Duschl, G. J. Oostingh, and V. Puntes, "Time evolution of the nanoparticle protein corona," ACS Nano, vol. 4, no. 7, pp. 3623-3632, 2010. 

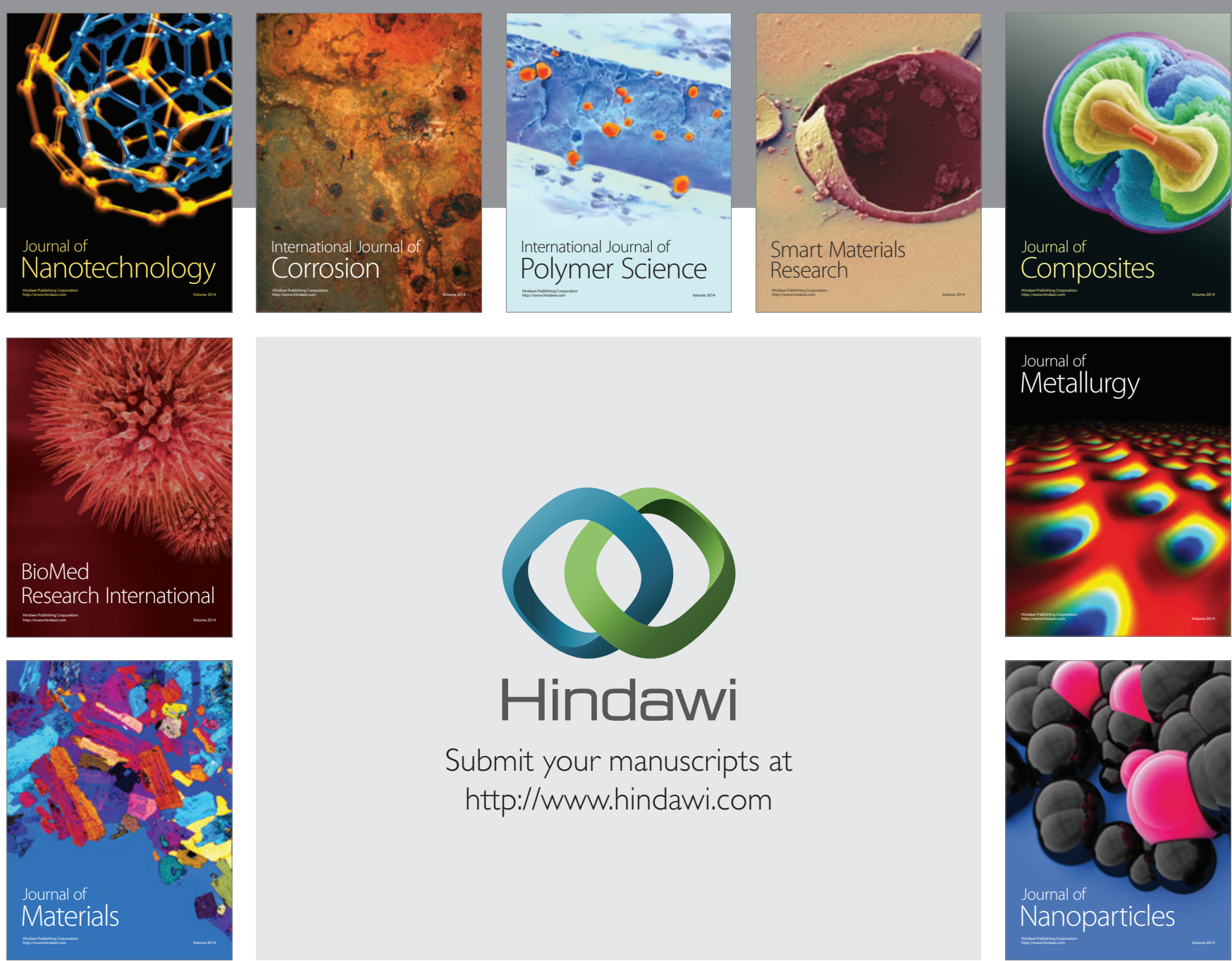

\section{Hindawi}

Submit your manuscripts at

http://www.hindawi.com

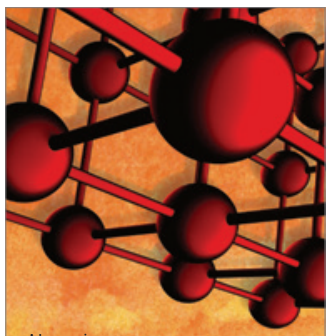

Materials Science and Engineering
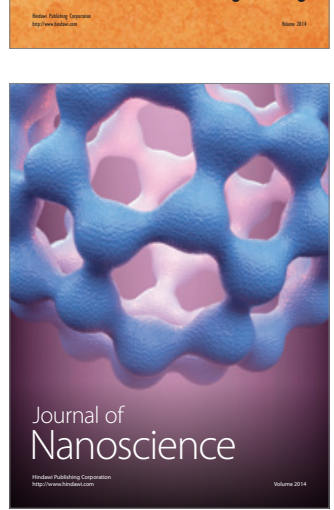
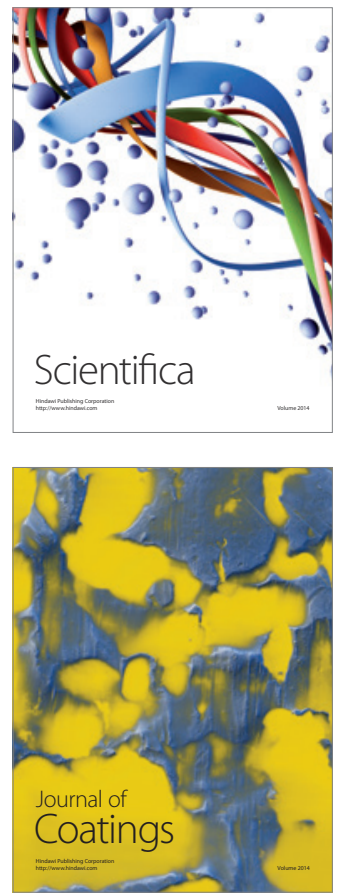
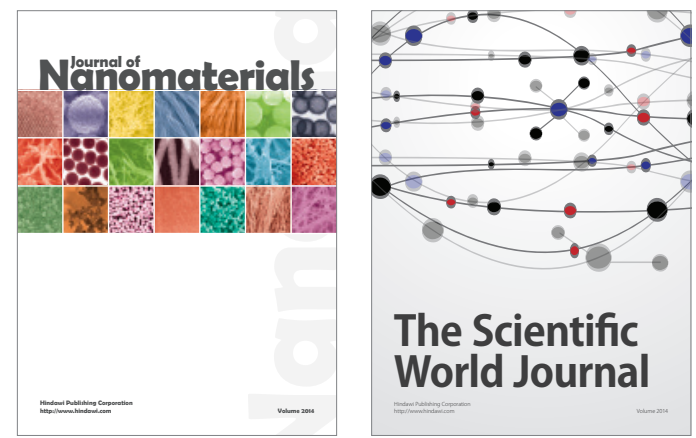

The Scientific World Journal
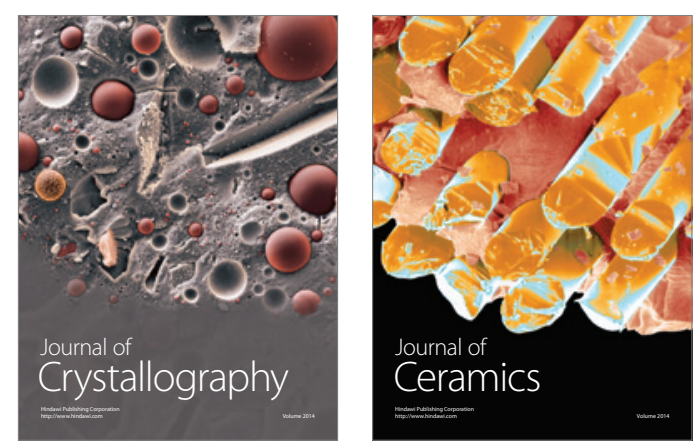
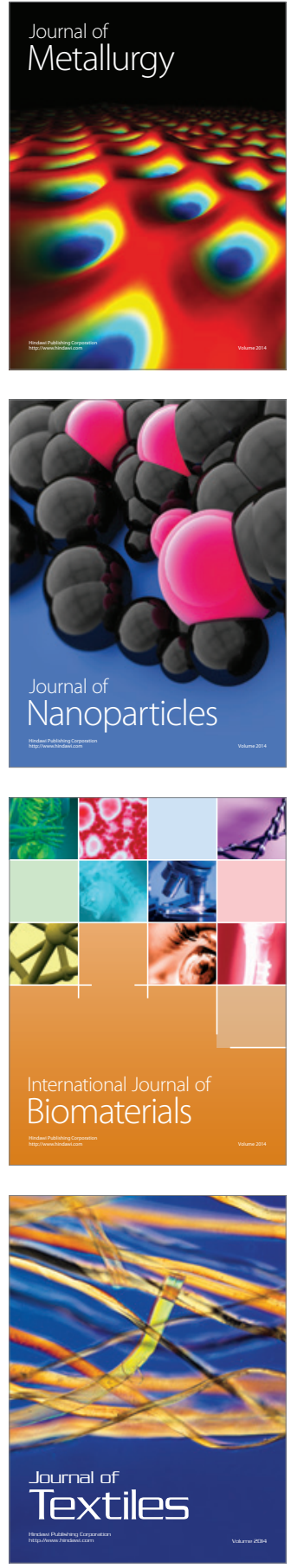